\title{
Aortic valve disease with ascending aortic aneurysm: Impact of concomitant root-sparing (supracoronary) aortic replacement in nonsyndromic patients
}

\author{
Sven Peterss, MD, a,b Paris Charilaou, MD, ${ }^{\mathrm{a}}$ Julia Dumfarth, MD, ${ }^{\mathrm{a}}$ Yupeng Li, BS, ${ }^{\mathrm{c}}$ Rohan Bhandari, MD, ${ }^{\mathrm{a}}$ \\ Maryann Tranquilli, RN, John A. Rizzo, PhD, ${ }^{\mathrm{a}, \mathrm{c}}$ Bulat A. Ziganshin, MD, ${ }^{\mathrm{a}, \mathrm{d}}$ and John A. Elefteriades, MD
}

\section{ABSTRACT}

Objective: The purpose of the study was to assess the anticipated incremental risk of a concomitant aortic resection performed with an aortic valve replacement.

Methods: Patients who underwent aortic valve replacement with root-sparing ascending replacement were compared with those who underwent isolated aortic valve replacement using propensity score matching (81 pairs; mean age, $63 \pm 11$ years [root-sparing ascending replacement] vs $64 \pm 14$ years). To evaluate the impact of the technique at distal site, 71 pairs of those undergoing root-sparing ascending replacement also were matched by propensity score according to distal anastomosis performed clamped and open under deep hypothermic circulatory arrest.

Results: Operative mortality was equal between the root-sparing ascending replacement and isolated aortic valve replacement groups. No significant difference was found regarding postoperative morbidities, such as bleeding, renal failure, stroke, and length of stay, except prolonged ventilation was found after root-sparing procedures $(P=.028)$. Survival estimation showed no difference between the groups. Comparing the patients undergoing root-sparing ascending replacement with clamped and opened distal anastomosis revealed a prolonged ventilation requirement ( $7 \%$ vs $3 \% ; P=$ not significant) in the open group. Operative mortality was $0 \%$ in both groups, and midterm survival was comparable.

Conclusions: The concomitant replacement of the aorta in root-sparing fashion is associated with an excellent operative outcome and adds no additional risk to aortic valve replacement in elective and non-high-risk patients. If the distal anastomosis is performed in an open fashion, while the operative mortality is still very low, morbidities are slightly higher, but midterm survival remains comparable. (J Thorac Cardiovasc Surg 2016;152:791-8)

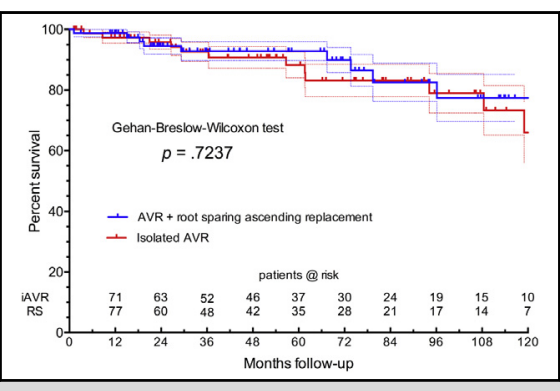

AVR with or without ascending aortic resection showed equal survival.

\section{Central Message}

Proximal aortic replacement with the RS technique is a safe approach and can be performed with excellent operative results.

\section{Perspective}

Resecting the mildly to moderately dilated aorta at the time of AVR adds no additional morbidity and mortality risk for patients. These data are highly relevant to surgical decision making regarding the management of the aorta at the time of AVR. These data help to weigh the operative risk of aortic resection against the natural risk of aortic dissection and rupture.

See Editorial Commentary page 799

\footnotetext{
From the a Aortic Institute at Yale-New Haven Hospital, Yale University School of Medicine, New Haven, Conn; ${ }^{b}$ Department of Cardiac Surgery, University Hospital Munich, Ludwig Maximilian University, Munich, Germany; ${ }^{\mathrm{c} D e p a r t m e n t}$ of Economics and Department of Preventive Medicine, Stony Brook University, Stony Brook, NY; and ${ }^{\mathrm{d}}$ Department of Surgical Diseases \#2, Kazan State Medical University, Kazan, Russia.

S.P. is supported by a research fellowship (PE 2206/1-1) of the Deutsche Forschungsgemeinschaft, Bonn, Germany.

Received for publication Sept 24, 2015; revisions received April 23, 2016; accepted for publication May 17, 2016; available ahead of print June 16, 2016.

Address for reprints: John A. Elefteriades, MD, Aortic Institute at Yale-New Haven Hospital, Yale University School of Medicine, Clinic Building CB317, 789 Howard Ave, New Haven, CT 06510 (E-mail: john.elefteriades@yale.edu). $0022-5223 / \$ 36.00$

Copyright (c) 2016 by The American Association for Thoracic Surgery http://dx.doi.org/10.1016/j.jtcvs.2016.05.020
}

Weighing the risk of surgical intervention against the subsequent risks of a disease is essential in recommending a treatment strategy. In case of co-incidences of aortic valve disease and proximal thoracic aortic aneurysm, the assumed additive risk of replacing the aortic vessel

Scanning this QR code will take you to supplemental table for this article. 


\section{Abbreviations and Acronyms}

AVR = aortic valve replacement

DHCA $=$ deep hypothermic circulatory arrest

iAVR $=$ isolated aortic valve replacement

RS $\quad$ root sparing

concomitantly during an aortic valve replacement (AVR) must be weighed against the potential risk of dissection and rupture when leaving the aorta alone. But, is there really a significant surgical risk from incremental aortic resection? Although a conduit replacement of the valve and the root, for example, using the Bentall technique, is known to add technical complexity, ${ }^{1,2}$ the rootsparing (RS) approach represents a less difficult technique, avoiding detachment and reattachment of the coronary ostia because the proximal anastomosis is done above the commissures of the native valve. ${ }^{3}$ Thus, the operative risk may not be substantial. The essential requirement for application of the RS technique is a nondiseased (not significantly dilated) root. In the 1990 s, Carrel and coworkers ${ }^{4}$ reported a mortality of $6.5 \%$ with a high incidence of postoperative morbidity for RS replacement compared with an isolated AVR (iAVR). However, since then, more complex aortic procedures have become clinically routine and are performed with excellent results in experienced centers. ${ }^{5}$ The aim of this study was to evaluate the modern-day risk of a concomitant RS supracoronary aortic replacement compared with the isolated approach of AVR. We also examined the impact of distal extension of the resection close or into the aortic arch.

\section{PATIENTS AND METHODS Study Design}

All consecutive patients undergoing AVR and RS (supracoronary) ascending aortic replacement by a single surgeon between 2004 and 2014 were reviewed for the present study. To compare the specific risk of a concomitant ascending aortic replacement-controlling for the general risk of a cardiac surgical procedure and the use of cardiopulmonary bypass - a contemporaneously operated control group of consecutive iAVRs was identified. Patients receiving an ascending replacement without an AVR were excluded from this study. Further exclusion criteria were total aortic arch replacement, aortic dissection, intramural hematoma, penetrating aortic ulcer, endocarditis, connective tissue disorder (Marfan, Ehlers-Danlos, Loeys-Dietz), transcatheter approaches, root replacement (Bentall, Cabrol, David, or Yacoub procedure), root remodeling, and concomitant coronary artery bypass grafting procedure.

Group propensities were adjusted by propensity score matching (details noted in "Statistical Analysis" section), and demographic characteristics, comorbidities, operative data, postoperative morbidity, and early outcome were analyzed by comparing the study group with the control group. Late complications were analyzed according to Akins and colleagues. ${ }^{6}$ In a second step, the population receiving RS procedures was divided into 2 subgroups according to distal extension into the arch (clamped vs open distal anastomosis) requiring the use of deep hypothermic circulatory arrest
(DHCA), and a comparison was performed after propensity score matching. Survival after discharge was determined from the Social Security Death Index and chart review, and the date of proven last clinical contact was used for the status "alive." The Human Investigation Committee of Yale University approved this retrospective study, and all patients signed informed consent.

\section{Patient Population}

Between 2004 and 2014, 182 consecutive patients with concomitant aortic valve and ascending aortic aneurysm disease (RS) (mean age, $61 \pm 13$ years; $60 \%$ were male) and 159 patients with isolated aortic valve disease (iAVR) (mean age, $70 \pm 13$ years; $59 \%$ were male) underwent operation at Yale-New Haven Hospital by 1 surgeon (JAE) and met the criteria of the present study. Among those, 81 pairs were matched for comparison using the propensity score model. The demographic and medical characteristics are presented in Table 1.

\section{Subgroup Population}

Among the 182 patients undergoing the concomitant AVR and RS procedure, 96 underwent an open distal anastomosis using DHCA and 86 received an approach limited to the ascending aorta without the need for DHCA. To compare outcomes for these 2 subgroups, we used matching techniques on them. Among those groups, 71 patients each matched for comparison using the propensity score model were included in the analysis. Demographics and characteristics are shown in Table 1.

\section{Surgical Indication and Procedure}

According to guidelines, a diameter of $45 \mathrm{~mm}$ represents the indication to concomitantly replace the aorta in case of an indicated cardiac procedure at the Aortic Institute. ${ }^{7}$ None of the patients in the iAVR group met this criterion. In the RS group, the aorta was replaced at a diameter of $45 \mathrm{~mm}$ or greater in 111 patients, 40 to $44 \mathrm{~mm}$ in 19 patients, and less than $40 \mathrm{~mm}$ in 6 patients, according to our institutional policy regarding co-incidental diseases and biometrical adjustment. ${ }^{8,9}$

All procedures were performed using a total median sternotomy. The aortic valve was implanted by an intra-annular technique, and the ascending aorta, if applicable, was resected above the aortic valve commissures. An open distal anastomosis was distinguished by the lack of supra-aortic branch disconnection and reimplantation. If circulatory arrest was applicable, deep core temperatures approaching $18^{\circ} \mathrm{C}$ to $19^{\circ} \mathrm{C}$ were used, followed by an extended warming. No adjunct selective organ perfusion technique was used.

\section{Statistical Analysis}

The matching between the respective groups was done by using a propensity score model including the following variables: age, gender, aortic valve stenosis, bicuspid valve morphology, symptomatic disease, arterial hypertension, pulmonary hypertension, left ventricular ejection fraction $35 \%$ or less, coronary artery disease, atrial fibrillation, history of smoking, chronic obstructive pulmonary disease, diabetes, chronic renal failure, hemodialysis, and history of stroke. The propensity score model was matched using nearest neighbor matching with a caliper of 0.25 . Matching covariates and standardized difference of the mean are shown in Figure 1 and Table E1.

Data are presented as frequency distributions and percentages for categoric variables or as mean \pm standard deviation for continuous variables. The Pearson chi-square test or Fisher exact test was used when analyzing categoric variables, the Student $t$ test or Mann-Whitney $U$ test was used for continuous variables, and the Kaplan-Meier survival estimate was used for survival analysis. The Gehan-Breslow-Wilcoxon test (for detecting significance mostly in the earlier time period) was used to compare the estimated survival of different populations. Statistical analysis and matching were performed using SPSS version 
TABLE 1. Demographics and characteristics

\begin{tabular}{|c|c|c|c|c|c|c|}
\hline \multirow[b]{3}{*}{$\mathbf{n}=$} & \multicolumn{6}{|c|}{ Propensity score-matched cohort } \\
\hline & iAVR & $\mathbf{A V R}+\mathbf{R S}$ & & Clamped anastomosis & Open distal anastomosis & \\
\hline & 81 & 81 & $P$ value & 71 & 71 & $P$ value \\
\hline Age, y & $63.5 \pm 13.6$ & $63.1 \pm 11.2$ & .821 & $60.4 \pm 11.6$ & $60.0 \pm 13.3$ & .861 \\
\hline Male gender & $55(68 \%)$ & $56(69 \%)$ & 1.000 & $48(68 \%)$ & $46(65 \%)$ & .859 \\
\hline BMI & $28.1 \pm 5.2$ & $28.2 \pm 5.9$ & .848 & $29.5 \pm 6.4$ & $28.3 \pm 5.9$ & .291 \\
\hline \multicolumn{7}{|l|}{ STS risk score } \\
\hline Operative mortality, $\%$ & $1.15 \pm 0.88$ & $1.07 \pm 0.66$ & .515 & $0.92 \pm 0.55$ & $0.99 \pm 0.62$ & .458 \\
\hline $\begin{array}{l}\text { Major morbidity or operative } \\
\text { mortality, } \%\end{array}$ & $10.15 \pm 3.43$ & $10.17 \pm 3.3$ & .972 & $9.38 \pm 2.94$ & $9.73 \pm 2.88$ & .472 \\
\hline \multicolumn{7}{|l|}{ Aortic valve disease } \\
\hline Stenosis & $63(78 \%)$ & $53(65 \%)$ & .116 & $44(62 \%)$ & $39(55 \%)$ & .496 \\
\hline Mean pressure gradient, $\mathrm{mm} \mathrm{Hg}$ & $48.7 \pm 13.7$ & $41.1 \pm 15.6$ & .014 & $44.5 \pm 17.2$ & $38.9 \pm 17.0$ & .188 \\
\hline Valve area, $\mathrm{cm}^{2}$ & $0.72 \pm 0.16$ & $0.90 \pm 0.34$ & .002 & $0.85 \pm 0.25$ & $0.97 \pm 0.39$ & .140 \\
\hline Insufficiency & $18(22 \%)$ & $28(35 \%)$ & .116 & $27(38 \%)$ & $32(45 \%)$ & .496 \\
\hline \multicolumn{7}{|l|}{ Valve morphology } \\
\hline Bicuspid & $56(69 \%)$ & $56(69 \%)$ & 1.000 & $58(82 \%)$ & $52(73 \%)$ & .315 \\
\hline \multicolumn{7}{|l|}{ Aortic diameter } \\
\hline Root & $33.8 \pm 5.3$ & $35.9 \pm 6.2$ & .112 & $37.4 \pm 6.7$ & $36.9 \pm 5.9$ & .729 \\
\hline Ascending & $34.8 \pm 4.4$ & $48.5 \pm 7.6$ & $<.001$ & $46.4 \pm 5.8$ & $50.6 \pm 7.6$ & $<.001$ \\
\hline Arch & $27.9 \pm 3.7$ & $28.9 \pm 5.0$ & .409 & $28.9 \pm 5.1$ & $30.6 \pm 5.5$ & .237 \\
\hline Bovine arch & $0(-)$ & $4(5 \%)$ & .120 & $1(1 \%)$ & $6(9 \%)$ & .116 \\
\hline \multicolumn{7}{|l|}{ Comorbidities } \\
\hline Symptomatic & $70(86 \%)$ & $63(78 \%)$ & .218 & $44(62 \%)$ & $43(61 \%)$ & 1.000 \\
\hline Arterial HT & $59(73 \%)$ & $66(82 \%)$ & .261 & $56(79 \%)$ & $55(78 \%)$ & 1.000 \\
\hline Pulmonary HT & $5(6 \%)$ & $5(6 \%)$ & 1.000 & $0(-)$ & $0(-)$ & - \\
\hline LVEF & $56.8 \pm 12.1$ & $56.8 \pm 10.4$ & .977 & $58.1 \pm 9.6$ & $57.8 \pm 8.6$ & .833 \\
\hline Coronary artery disease & $10(12 \%)$ & $10(12 \%)$ & 1.000 & $6(9 \%)$ & $8(11 \%)$ & .779 \\
\hline Atrial fibrillation & $7(9 \%)$ & $7(9 \%)$ & 1.000 & $5(7 \%)$ & $6(9 \%)$ & 1.000 \\
\hline History of smoking & $32(40 \%)$ & $26(32 \%)$ & .413 & $20(28 \%)$ & $23(32 \%)$ & .715 \\
\hline COPD & $11(14 \%)$ & $6(7 \%)$ & .305 & $5(7 \%)$ & $4(6 \%)$ & 1.000 \\
\hline Dyslipidemia & $46(57 \%)$ & $43(53 \%)$ & .752 & $40(56 \%)$ & $39(55 \%)$ & 1.000 \\
\hline Diabetes & $13(16 \%)$ & $14(17 \%)$ & 1.000 & $10(14 \%)$ & $12(17 \%)$ & .817 \\
\hline Chronic renal failure & $5(6 \%)$ & $4(5 \%)$ & 1.000 & $1(1 \%)$ & $2(3 \%)$ & 1.000 \\
\hline Creatinine & $0.91 \pm 0.28$ & $0.89 \pm 0.23$ & .373 & $0.86 \pm 0.21$ & $0.91 \pm 0.23$ & .156 \\
\hline History of stroke & $4(5 \%)$ & $4(5 \%)$ & 1.000 & $2(3 \%)$ & $3(4 \%)$ & 1.000 \\
\hline
\end{tabular}

23.0 (IBM Inc, Armonk, NY) in cooperation with the Departments of Economics and Preventive Medicine of Stony Brook University (Stony Brook, NY).

\section{RESULTS \\ Operative Data}

In the propensity score-corrected population, cardiopulmonary bypass times were $91.1 \pm 14.4$ minutes (iAVR) and $144.1 \pm 25.7$ minutes $(\mathrm{RS})(P<.001)$, and crossclamp times were $68.0 \pm 11.7$ minutes (iAVR) and $99.8 \pm 13.9$ minutes (RS) $(P<.001)$, and thus differ by 53 and 32 minutes. Distal anastomosis was performed open in $53 \%$ of the patients, requiring $25.9 \pm 3.7$ minutes of circulatory arrest at $19.1^{\circ} \mathrm{C} \pm 0.8^{\circ} \mathrm{C}$ on average. No additional selective cerebral perfusion strategy was used according to our institutional protocol. ${ }^{10}$ Technical complications were noted in $3 \%$ of patients (RS) and $1 \%$ of patients (iAVR), in the majority of the cases represented by a secondary change of the valve prosthesis to a smaller size or reconstruction of the femoral artery due to arterial cannulation. Further operative details are noted in the Appendix (Table 2).

\section{Postoperative Outcome}

Among the propensity score-corrected comparison, patients undergoing concomitant aortic surgery experienced a higher incidence of prolonged ventilation (7\% vs $0 \%, P=.028)$ and longer stay in the intensive care unit (3.7 \pm 3.5 days vs $2.8 \pm 1.5$ days, $P=.025)$. In-hospital 

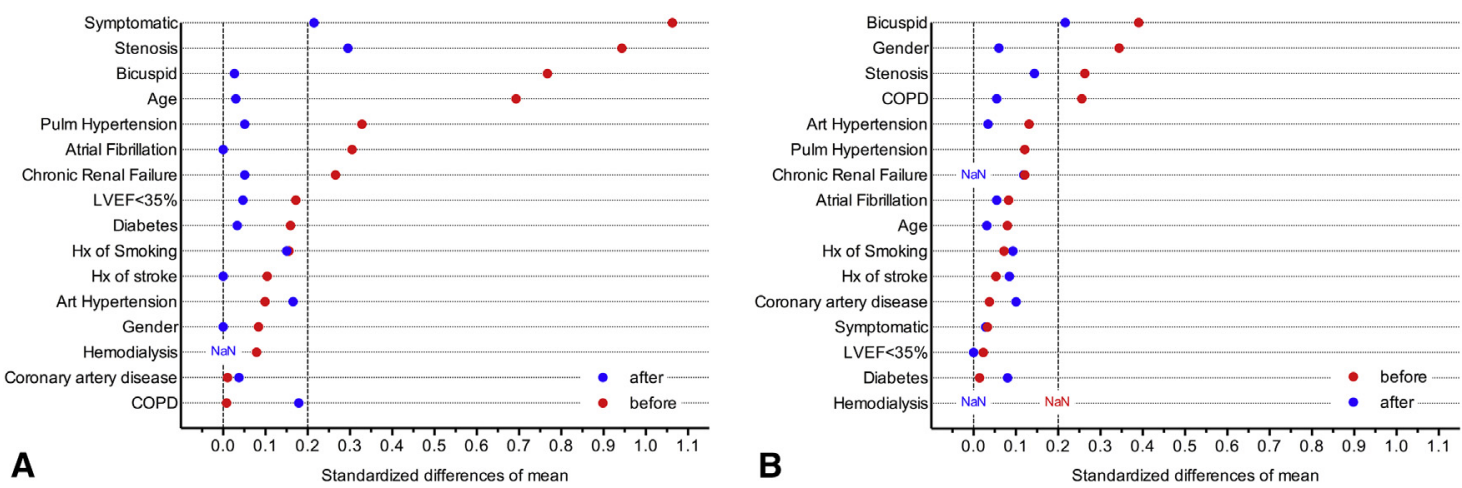

FIGURE 1. Covariate balance for (A) study analysis and (B) subgroup analysis before and after propensity score matching. pulm, Pulmonary; $L V E F$, left ventricular ejection fraction; $h x$, history; Art, arterial; $C O P D$, chronic obstructive pulmonary disease.

stay and other comorbidities, such as bleeding, renal failure, and stroke, showed no difference between the groups. Operative mortality was $0 \%$ in both groups. Details are shown in Table 3.

\section{Follow-up and Survival}

Survival expressed by the Kaplan-Meier survival estimation in Figure 2 showed no significant difference between the groups $(P=.7237)$.

During follow-up, no patient in the RS group required a secondary root replacement due to progressive root dilation; only 1 patient had a pseudoaneurysm of the suture line (infection) and underwent redo ascending replacement 4 months after prior surgery.
Mean follow-up time was $4.7 \pm 3.4$ years (RS) and $4.9 \pm 3.4$ years (iAVR). No significant differences were found in late complications regarding secondary aortic valve replacement, complete heart block, pericardial and pleural effusion, left ventricular ejection fraction decline, need for automated implantable cardioverterdefibrillator, transitory ischemic attack, stroke, endocarditis, renal failure, patient-prosthesis mismatch, or structural and nonstructural prosthesis deterioration after discharge.

\section{Distal Anastomosis Technique (Subgroup Analysis)}

The subgroup analysis of the concomitant RS ascending replacement cases, divided according to the type of distal

TABLE 2. Operative data

\begin{tabular}{|c|c|c|c|c|c|c|}
\hline & \multicolumn{6}{|c|}{ Propensity score-matched cohort } \\
\hline & iAVR & $\mathbf{A V R}+\mathbf{R S}$ & $P$ value & Clamped anastomosis & Open distal anastomosis & $P$ value \\
\hline $\mathrm{CPB}$ time, $\min$ & $91.1 \pm 14.4$ & $144.1 \pm 25.7$ & $<.001$ & $127.3 \pm 16.3$ & $159.9 \pm 18.8$ & $<.001$ \\
\hline Crossclamp time, $\min$ & $68.0 \pm 11.7$ & $99.8 \pm 13.9$ & $<.001$ & $103.3 \pm 14.2$ & $98.6 \pm 15.4$ & .066 \\
\hline DHCA & $0(-)$ & $43(53 \%)$ & $<.001$ & $0(-)$ & $71(100 \%)$ & $<.001$ \\
\hline DHCA time, $\min$ & - & $25.9 \pm 3.7$ & - & - & $25.6 \pm 4.9$ & - \\
\hline Lowest core temperature, ${ }^{\circ} \mathrm{C}$ & - & $19.1 \pm 0.8$ & - & - & $18.9 \pm 0.6$ & - \\
\hline \multicolumn{7}{|l|}{ Arterial cannulation } \\
\hline Ascending aorta/arch & $81(100 \%)$ & $10(12 \%)$ & $<.001$ & $9(13 \%)$ & $3(4 \%)$ & .129 \\
\hline Femoral artery & $0(-)$ & $67(83 \%)$ & $<.001$ & $61(86 \%)$ & $66(93 \%)$ & .275 \\
\hline Axillary artery & $0(-)$ & $4(5 \%)$ & .120 & $1(1 \%)$ & $2(3 \%)$ & 1.000 \\
\hline \multicolumn{7}{|l|}{ Prosthesis } \\
\hline Mechanical & $39(48 \%)$ & $34(42 \%)$ & .528 & $35(49 \%)$ & $35(49 \%)$ & 1.000 \\
\hline Biological & $42(52 \%)$ & $47(58 \%)$ & & $36(51 \%)$ & $36(51 \%)$ & \\
\hline Size, $\mathrm{mm}$ & $21.6 \pm 2.2$ & $22.3 \pm 2.0$ & .049 & $22.5 \pm 2.0$ & $22.5 \pm 2.2$ & .967 \\
\hline \multicolumn{7}{|l|}{ Primary procedure } \\
\hline RS technique & - & $81(100 \%)$ & - & $71(100 \%)$ & $71(100 \%)$ & - \\
\hline Open distal anastomosis & - & $43(53 \%)$ & - & $0(-)$ & $71(100 \%)$ & - \\
\hline Concomitant procedure & $9(11 \%)$ & $15(19 \%)$ & .269 & $12(17 \%)$ & $11(16 \%)$ & 1.000 \\
\hline Annuloplasty & $1(1 \%)$ & $0(-)$ & 1.000 & $0(-)$ & $0(-)$ & - \\
\hline Technical complication & $1(1 \%)$ & $2(3 \%)$ & 1.000 & $3(4 \%)$ & $4(6 \%)$ & 1.000 \\
\hline
\end{tabular}


TABLE 3. Early postoperative outcome

\begin{tabular}{|c|c|c|c|c|c|c|}
\hline & \multicolumn{6}{|c|}{ Propensity score-matched cohort } \\
\hline & iAVR & $\mathbf{A V R}+\mathbf{R S}$ & $P$ value & Clamped anastomosis & Open distal anastomosis & $P$ value \\
\hline Reexploration due to bleeding & $5(6 \%)$ & $4(5 \%)$ & 1.000 & $4(6 \%)$ & $3(4 \%)$ & 1.000 \\
\hline \multicolumn{7}{|l|}{ Morbidity } \\
\hline Ventilation $>48 \mathrm{~h}$ & $0(-)$ & $6(7 \%)$ & .028 & $2(3 \%)$ & $5(7 \%)$ & .441 \\
\hline LCOS & $0(-)$ & $1(1 \%)$ & 1.000 & $1(1 \%)$ & $1(1 \%)$ & 1.000 \\
\hline With IABP & $3(4 \%)$ & $3(4 \%)$ & 1.000 & $1(1 \%)$ & $1(1 \%)$ & 1.000 \\
\hline With ECLS/ECMO & $0(-)$ & $1(1 \%)$ & 1.000 & $0(-)$ & $1(1 \%)$ & 1.000 \\
\hline Myocardial infarction & $0(-)$ & $1(1 \%)$ & 1.000 & $0(-)$ & $1(1 \%)$ & 1.000 \\
\hline Atrial fibrillation* & $9(11 \%)$ & $7(9 \%)$ & .793 & $6(9 \%)$ & $5(7 \%)$ & 1.000 \\
\hline AV block III* & $7(9 \%)$ & $4(5 \%)$ & .534 & $4(6 \%)$ & $6(9 \%)$ & .745 \\
\hline Pacemaker & $10(12 \%)$ & $4(5 \%)$ & .160 & $4(6 \%)$ & $6(9 \%)$ & .745 \\
\hline Renal failure* & $4(5 \%)$ & $4(5 \%)$ & 1.000 & $2(3 \%)$ & $3(4 \%)$ & 1.000 \\
\hline Stroke & $1(1 \%)$ & $1(1 \%)$ & 1.000 & $0(-)$ & $1(1 \%)$ & 1.000 \\
\hline Infection & $6(7 \%)$ & $5(6 \%)$ & 1.000 & $2(3 \%)$ & $2(3 \%)$ & 1.000 \\
\hline Sepsis & $0(-)$ & $0(-)$ & - & $0(-)$ & $0(-)$ & - \\
\hline Composite morbidity $\dagger$ & $10(12 \%)$ & $11(14 \%)$ & 1.000 & $8(11 \%)$ & $10(14 \%)$ & .802 \\
\hline \multicolumn{7}{|l|}{ Length of stay } \\
\hline ICU, d & $2.8 \pm 1.5$ & $3.7 \pm 3.5$ & .025 & $2.9 \pm 1.4$ & $3.5 \pm 3.0$ & .143 \\
\hline Median (25-75 percentile) & $3.0(2.0-3.0)$ & $3.0(2.0-4.0)$ & .029 & $2.0(2.0-3.0)$ & $3.0(2.0-4.0)$ & .323 \\
\hline In-hospital, d & $5.9 \pm 1.9$ & $6.4 \pm 4.0$ & .321 & $5.6 \pm 1.3$ & $6.1 \pm 3.6$ & .231 \\
\hline Median (25-75 percentile) & $5.0(5.0-6.0)$ & $5.0(5.0-6.0)$ & .520 & $5.0(5.0-6.0)$ & $5.0(5.0-6.0)$ & .596 \\
\hline Operative mortality $\ddagger$ & $0(-)$ & $0(-)$ & - & $0(-)$ & $0(-)$ & - \\
\hline 1-y survival, $\%$ & $97.3 \pm 1.9$ & $98.8 \pm 1.2$ & & $100 \pm 0$ & $98.6 \pm 1.4$ & \\
\hline 5 -y survival, $\%$ & $88.3 \pm 4.3$ & $92.8 \pm 3.1$ & & $98.4 \pm 1.6$ & $95.6 \pm 2.5$ & \\
\hline
\end{tabular}

Data are shown as mean \pm standard deviation, number (percentage) or as [reported]. Bold values are statistically significant $(P<.05) . i A V R$, Isolated aortic valve replacement; $A V R$, aortic valve replacement; $R S$, root-sparing; $L C O S$, low cardiac output syndrome; IABP, intra-aortic balloon pump; ECLS, extracorporeal life support; $E C M O$, extracorporeal membrane oxygenation; $A V$, aortic valve; $I C U$, intensive care unit. *Postoperative new-onset. †Including reexploration, prolonged ventilation, stroke, renal failure, low cardiac output syndrome, and sepsis. $\ddagger$ Classified as in-hospital mortality plus 30-day mortality of discharged patients; length of stay refers to the postoperative period.

anastomosis (open and with DHCA or clamped and without DHCA), showed no significant differences in the postoperative morbidity, mortality, and length of stay. The stroke rate was low in both subgroups, with $0 \%$ (an approach limited to the ascending aorta without the need for

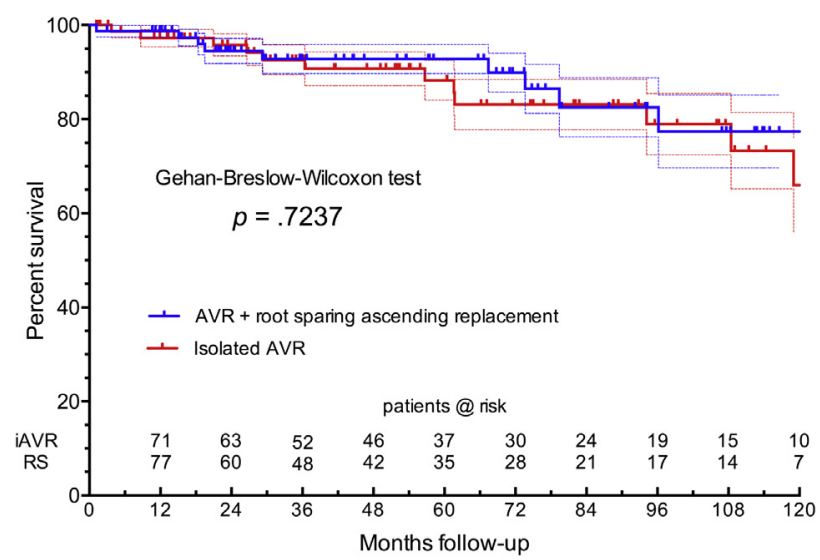

FIGURE 2. Kaplan-Meier survival estimation after propensity score matching of the concomitant RS aortic replacement group compared with the control group undergoing an iAVR approach. AVR, Aortic valve replacement; $i A V R$, isolated aortic valve replacement; $R S$, root sparing.
DHCA) and 1\% (open distal anastomosis using DHCA). Midterm analysis showed comparable survival in patients who underwent open extension with DHCA compared with those with a clamped distal anastomosis in midterm view $(P=.0533)$. However, long-term survival differed significantly between the distal anastomosis type groups, from year 5 onward (log rank [Mantel-Cox] test: $P=.0213$ ). Survival is shown in Figure 3, and further details are outlined in Tables 2 and 3.

\section{DISCUSSION}

Aortic valve disease and ascending aortic aneurysm are often associated with various causes. In addition to hemodynamic flow patterns with aberrant mechanical forces causing a poststenotic aortic dilation, intrinsic genetic and physiologic abnormalities of the aortic wall are known to be at play (eg, Marfan disease, bicuspid aortic valves). ${ }^{9}$ Moreover, an aneurysm of the aorta itself can cause aortic valve insufficiency by dilating the valve scaffold and reducing the coaptation area of the cusps. In case of the co-incidence of both diseases (diseased aortic valve and aorta), it still remains controversial whether a more preventive approach or a more restrained posture regarding the aorta is indicated. ${ }^{11}$ Opponents of an aggressive 


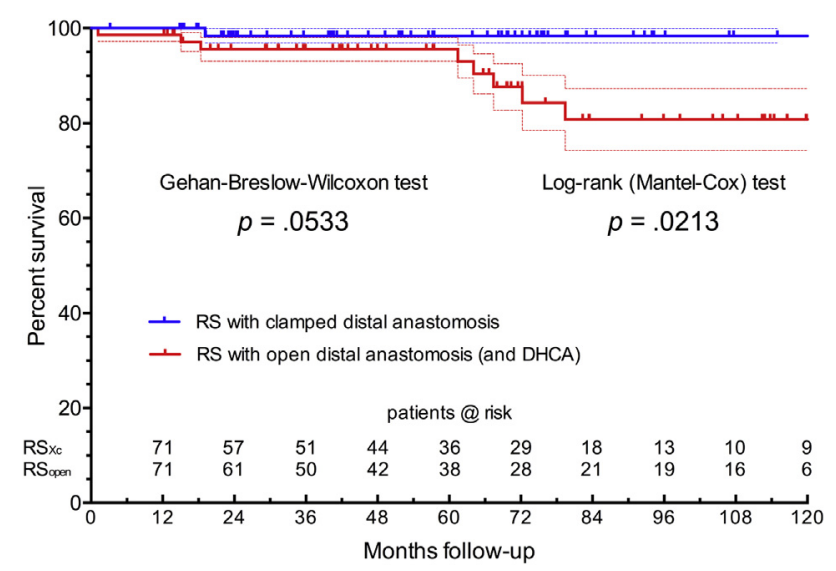

FIGURE 3. Kaplan-Meier survival estimation after propensity score matching comparing clamped technique for distal site and open distal anastomosis (with DHCA). RS, Root-sparing; DHCA, deep hypothermic circulatory arrest; $R S_{X c}$, approach limited to the ascending aorta without the need for DHCA; $R S_{\text {open }}$, open distal anastomosis using DHCA.

approach argue that a concomitant aortic replacement increases the operative risk compared with an isolated valve replacement.

This study shows that adding an RS ascending aortic replacement—representing the surgically simplest approach regarding the proximal anastomosis of the diseased aorta-is associated with no higher operative risk than an iAVR. In fact, this risk was $0 \%$. The overall incidence of postoperative morbidity also was low, especially regarding the reexploration rate $(4 \%)$ and postoperative strokes $(1 \%)$. Only a higher incidence of prolonged ventilation $(7 \%$ vs $0 \%)$ was found. Intensive care unit and in-hospital stays were brief (2-4 and 56 days, respectively). None of the patients with concomitant aortic surgery died within 30 days.

Studies from the University of Virginia, University of Toronto, Northwestern University, and, most recently, University of Udine, focusing on bicuspid valves, presented similarly favorable results and confirm the safety of the RS approach found in the present study. ${ }^{12-15}$

Even by extending the surgical approach close to or into the arch portion (with an open distal anastomosis and the need for DHCA), the postoperative outcomes remained favorable, with a mortality of $0 \%$. Because of the more complex operative approach, a slightly higher incidence of prolonged ventilation $(5 \%-7 \%$ vs $3 \%-4 \%)$, renal failure ( $4 \%$ vs $2 \%-3 \%)$, and postoperative need for antibiotic treatment (infection 3\%-5\% vs $2 \%-3 \%$ ) were found. An open distal anastomosis represents an entirely resected ascending portion without remaining residual. We think the open distal anastomosis is a technically easier approach, reflected by a decreased crossclamp time of 4 to 5 minutes (Table 2). However, this technique also requires hypothermic circulatory arrest with a consequently prolonged time on cardiopulmonary bypass due to cooling and rewarming (32-33 minutes in the present study) and the necessity of a cerebral protection strategy.

At our institution, straight deep hypothermic arrest (targeting $18^{\circ} \mathrm{C}-19^{\circ} \mathrm{C}$ ) represents the established routine of brain and organ protection. In a former study by our group, Gega and colleagues ${ }^{16}$ found a stroke rate of $2.3 \%$ and mortality of $2.0 \%$ in elective cases using this technique. Later, Ziganshin and colleagues ${ }^{10}$ confirmed these good results, analyzing arch replacements and reporting strokes in $1.2 \%$ and early mortality in $1.4 \%$ of the cases, one third due to cerebral-associated causes. The safe duration of DHCA was evaluated as within 40 and 50 minutes in these studies. In comparison with adjunct brain protection techniques, straight DHCA was found as effective as more complex perfusion approaches and furthermore provides an unimpaired surgical view by the lack of additional perfusion catheters in or cannulas close by the operative field. ${ }^{17,18}$ In the present study, the mean time of DHCA was completely within the safe period, lasting 25 to 26 minutes on average, with a range from 11 to 46 minutes. Femoral cannulation represents our standard technique and provides simplicity and effectiveness. ${ }^{19,20}$ We reserve an axillary approach for cases with a "dirty" aorta on preoperative computed tomography or intraoperative transesophageal echocardiography.

Is sparing the root and leaving a portion of the very proximal native aortic tissue a sufficient approach or do we risk the manifestation of root aneurysms later? Replacing the root as a redo procedure certainly is associated with an appreciable operative risk and mortality. By analyzing the biomechanical parameters of a spared root, Simon-Kupilik and coworkers ${ }^{21}$ found a significant increase of hemodynamic burden after ascending graft replacement. They reported an increase in the wall stress index in the native root of $22 \%$ (in vitro) and $16 \%$ (in vivo). Rinewalt and colleagues ${ }^{12}$ advocated a more aggressive intervention, recommending Bentall procedures to avoid reoperations. However, in our opinion, sparing the root is a legitimate technique for 2 reasons: First, a replacement of the root requiring reimplantation of the coronary arteries is associated with a slightly higher operative risk. ${ }^{2}$ In a large meta-analysis, Castrovinci and colleagues $^{22}$ found a stroke rate of $3.7 \%$ (range, $0 \%-29 \%$ ), myocardial infarction rate of $2.9 \%$ (range, $0 \%-13 \%$ ), and bleeding complications requiring operative reexploration rate of $7.6 \%$ (range, $0 \%-27 \%$ ). In-hospital mortality was $6.4 \%$ (range, $0 \%-25 \%$ ). Second, the aortic root grows slowly, slower than the other portions of the aorta. In a recent analysis from our institution, the growth rate was found at $0.41 \mathrm{~mm}$ per year (range, $0.27-0.51 \mathrm{~mm} /$ year according to the initial diameter 
[25-50 mm]), regardless of valve morphology or concomitant valve replacement. We calculated (on the basis of a comparable mean root diameter as in the present study) and according to our institutional criteria (root replacement at $50 \mathrm{~mm}$ ) that subsequent aortic root replacement would not be required for 29 years or more. ${ }^{23}$ The most recent findings of Vendramin and coworkers ${ }^{15}$ clinically support these data.

As mentioned in the beginning of this article, the separation of benefit from harm is essential but difficult. It still remains controversial in the literature which aortic diameter triggers the surgical decision for aortic intervention in cases of primary aortic valve disease. Also controversial is whether bicuspid valve morphology indicates a resection at earlier stages. ${ }^{11,24-28}$ Verma and colleagues ${ }^{11}$ analyzed (using a survey) the variety of aortic treatments in the presence of bicuspid valve morphology among Canada's adult cardiac surgeons. They found that the threshold for resection the aorta in case of a nondiseased bicuspid valve was $55 \%$ at $50 \mathrm{~mm}$ and $23 \%$ at $45 \mathrm{~mm}$, whereas a diseased valve lowers the threshold to $45 \mathrm{~mm}$ in $61 \%$ and to $40 \mathrm{~mm}$ in $29 \%$ of the surgeons' decisions. However, the good results reported in the current article and others ${ }^{12-15}$ for the RS approach advocate for a more liberal treatment in elective patients.

Despite our institutional policy and the guidelines recommending concomitant aortic replacement at a diameter of $45 \mathrm{~mm}$ (Class I, evidence level B), ${ }^{29}$ it must be recognized that the risk of subsequent aortic events after iAVR consistently has been low. In patients presenting with a diameter larger than $40 \mathrm{~mm}$ during initial iAVR, McKellar and colleagues $^{30}$ from the Mayo Clinic found (analyzing exclusively bicuspid morphologies) only slightly less freedom from aortic events (aortic dissection, surgery, and enlargement) of $75 \%$ to $85 \%$ within 15 years, compared with those with smaller diameter (88\%-93\% freedom). In a recent study neglecting initial diameter, Itagaki and colleagues $^{31}$ from the Mount Sinai group reported a generally low incidence of aortic-related diseases after iAVR. The 15-year cumulative incidence of aortic dissection, aortic aneurysm, and the need for thoracic aortic surgery was $0.6 \%, 4.8 \%$, and $2.5 \%$, respectively, for patients with bicuspid valve morphology and $0.4 \%$, $1.4 \%$, and $0.5 \%$, respectively, for nonbicuspid and non-Marfan cases. Following the current guidelines, no aortic event (aortic dissection or need for thoracic aortic surgery) occurred in our patients undergoing iAVR during follow-up in the present study. We have shown that concomitant aortic surgery can be performed safely, but we have not proven that this was necessary.

\section{Study Limitations}

This is a retrospective study with the inherent limitations for such an analysis. We caution regarding the extrapolation of our results to higher-risk older patients. Also, we used a single cutoff value ( $45 \mathrm{~mm}$ ascending diameter) for the decision to resect the ascending aorta. Although this cutoff, representing our institutional policy, is consistent with guidelines, ${ }^{29}$ our study cannot determine the appropriate criterion (eg, in the range of $40-50 \mathrm{~mm}$ ) for concomitant aortic resection at the time of AVR. A randomized study would be necessary to focus on diameters between 40 and $50 \mathrm{~mm}$, including cofactors such as height, family history of dissection/rupture, connective tissue disorders, valve morphology, and other "associations." 9 This study represents a single-surgeon observation. Although such types of patient cohorts are limited in number and thus the potential number after matching is limited, it also provides uniformity in decision making, treatment, surgical quality, and clinical experience, which may counterbalance the detriments. Despite these limitations in statistical criteria and variables, we should not lose track of the main findings of this study: The technical performance of incremental concomitant supracoronary aortic replacement can be accomplished at a low surgical risk $(0 \%$ in this study).

\section{CONCLUSIONS}

Concomitant aortic valve and RS aortic replacement can be performed as safely as an iAVR in elective patients. If an extension close to or into the arch portion is advised, the operative mortality is still low and morbidity is slightly higher, but survival remains comparable. Thus, in experienced centers, an RS ascending replacement in aneurysmal patients, without a dilated aortic root and without syndromic connective tissue disorder, can be performed in addition to AVR without hesitation; furthermore, an open distal anastomosis, if necessary, should not be ruled out.

\section{Conflict of Interest Statement}

Authors have nothing to disclose with regard to commercial support.

\section{References}

1. Maddalo S, Beller J, DeAnda A. A Bentall is not a Bentall is not a Bentall: the evolution of aortic root surgery. Aorta. 2014;2:169-78.

2. Shahriari A, Eng M, Tranquilli M, Elefteriades JA. Rescue coronary artery bypass grafting (CABG) after aortic composite graft replacement. J Card Surg. 2009;24:392-6.

3. Wheat MW Jr, Wilson JR, Bartley TD. Successful replacement of the entire ascending aorta and aortic valve. JAMA. 1964;188:717-9.

4. Carrel T, von Segesser L, Jenni R, Gallino A, Egloff L, Bauer E, et al. Dealing with dilated ascending aorta during aortic valve replacement: advantages of conservative surgical approach. Eur J Cardiothorac Surg. 1991;5: 137-43.

5. Achneck HE, Rizzo JA, Tranquilli M, Elefteriades JA. Safety of thoracic aortic surgery in the present era. Ann Thorac Surg. 2007;84:1180-5.

6. Akins CW, Miller DC, Turina MI, Kouchoukos NT, Blackstone EH, Grunkemeier GL, et al. Guidelines for reporting mortality and morbidity after cardiac valve interventions. J Thorac Cardiovasc Surg. 2008;135:732-8.

7. Elefteriades JA. Indications for aortic replacement. J Thorac Cardiovasc Surg. 2010;140:S5-9. 
8. Davies RR, Gallo A, Coady MA, Tellides G, Botta DM, Burke B, et al. Novel measurement of relative aortic size predicts rupture of thoracic aortic aneurysms. Ann Thorac Surg. 2006;81:169-77.

9. Elefteriades JA, Sang A, Kuzmik G, Hornick M. Guilt by association: paradigm for detecting a silent killer (thoracic aortic aneurysm). Open Heart. 2015;2: e000169.

10. Ziganshin BA, Rajbanshi BG, Tranquilli M, Fang H, Rizzo JA, Elefteriades JA. Straight deep hypothermic circulatory arrest for cerebral protection during aortic arch surgery: safe and effective. J Thorac Cardiovasc Surg. 2014;148:888-98.

11. Verma S, Yanagawa B, Kalra S, Ruel M, Peterson MD, Yamashita MH, et al. Knowledge, attitudes, and practice patterns in surgical management of bicuspid aortopathy: a survey of 100 cardiac surgeons. J Thorac Cardiovasc Surg. 2013; 146:1033-40.e4.

12. Rinewalt D, McCarthy PM, Malaisrie SC, Fedak PW, Andrei AC, Puthumana JJ, et al. Effect of aortic aneurysm replacement on outcomes after bicuspid aortic valve surgery: validation of contemporary guidelines. J Thorac Cardiovasc Surg. 2014;148:2060-9.

13. Sioris T, David TE, Ivanov J, Armstrong S, Feindel CM. Clinical outcomes after separate and composite replacement of the aortic valve and ascending aorta. J Thorac Cardiovasc Surg. 2004;128:260-5.

14. Reece TB, Singh RR, Stiles BM, Peeler BB, Kern JA, Tribble CG, et al. Replacement of the proximal aorta adds no further risk to aortic valve procedures. Ann Thorac Surg. 2007;84:473-8.

15. Vendramin I, Meneguzzi M, Sponga S, Deroma L, Cimarosti R, Lutman C, et al. Bicuspid aortic valve disease and ascending aortic aneurysm: should an aortic root replacement be mandatory?†. Eur J Cardiothorac Surg. 2016;49: 103-9.

16. Gega A, Rizzo JA, Johnson MH, Tranquilli M, Farkas EA, Elefteriades JA. Straight deep hypothermic arrest: experience in 394 patients supports its effectiveness as a sole means of brain preservation. Ann Thorac Surg. 2007;84: 759-66.

17. Khaladj N, Shrestha M, Meck S, Peterss S, Kamiya H, Kallenbach K, et al. Hypothermic circulatory arrest with selective antegrade cerebral perfusion in ascending aortic and aortic arch surgery: a risk factor analysis for adverse outcome in 501 patients. J Thorac Cardiovasc Surg. 2008;135:908-14.

18. Ziganshin BA, Elefteriades JA. Deep hypothermic circulatory arrest. Ann Cardiothorac Surg. 2013;2:303-15.

19. Ayyash B, Tranquilli M, Elefteriades JA. Femoral artery cannulation for thoracic aortic surgery: safe under transesophageal echocardiographic control. J Thorac Cardiovasc Surg. 2011;142:1478-81.
20. Tsiouris A, Elkinany S, Ziganshin BA, Elefteriades JA. Open Seldinger-guided femoral artery cannulation technique for thoracic aortic surgery. Ann Thorac Surg. 2016;101:2231-5.

21. Simon-Kupilik N, Schima H, Huber L, Moidl R, Wipplinger G, Losert U, et al. Prosthetic replacement of the aorta is a risk factor for aortic root aneurysm development. Ann Thorac Surg. 2002;73:455-9.

22. Castrovinci S, Tian DH, Murana G, Cefarelli M, Berretta P, Alfonsi J, et al. Aortic root replacement with biological valved conduits. Ann Thorac Surg. 2015;100: 337-53.

23. Peterss S, Bhandari R, Rizzo JA, Fang H, Kuzmik G, Ziganshin BA, et al. The aortic root: natural history after root-sparing ascending replacement in non-syndromic patients. Ann Thorac Surg. 2016 [in press].

24. Elefteriades JA. Editorial comment: should aortas in patients with bicuspid aortic valve really be resected at an earlier stage than those in patients with tricuspid valve? Cardiol Clin. 2010;28:315-6.

25. Braverman AC. Guidelines for management of bicuspid aortic valve aneurysms: what's the clinician to do? Curr Opin Cardiol. 2014;29:489-91.

26. Michelena HI, Khanna AD, Mahoney D, Margaryan E, Topilsky Y, Suri RM, et al. Incidence of aortic complications in patients with bicuspid aortic valves. JAMA. 2011;306:1104-12.

27. Girdauskas E, Disha K, Borger MA, Kuntze T. Long-term prognosis of ascending aortic aneurysm after aortic valve replacement for bicuspid versus tricuspid aortic valve stenosis. J Thorac Cardiovasc Surg. 2014; 147:276-82.

28. Charitos EI, Stierle U, Petersen M, Mohamed SA, Hanke T, Schmidtke C, et al. The fate of the bicuspid valve aortopathy after aortic valve replacement. Eur J Cardiothorac Surg. 2014;45:e128-35.

29. Hiratzka LF, Bakris GL, Beckman JA, Bersin RM, Carr VF, Casey DE Jr, et al. 2010 Guidelines for the diagnosis and management of patients with thoracic aortic disease. J Am Coll Cardiol. 2010;55:e27-129.

30. McKellar SH, Michelena HI, Li Z, Schaff HV, Sundt TM III. Long-term risk of aortic events following aortic valve replacement in patients with bicuspid aortic valves. Am J Cardiol. 2010;106:1626-33.

31. Itagaki S, Chikwe JP, Chiang YP, Egorova NN, Adams DH. Long-term risk for aortic complications after aortic valve replacement in patients with bicuspid aortic valve versus Marfan syndrome. J Am Coll Cardiol. 2015; 65:2363-9.

Key Words: aneurysm, aortic root, aortic valve replacement, surgical risk 
TABLE E1. Matching model results

\begin{tabular}{|c|c|c|}
\hline \multirow[b]{3}{*}{ n per group $=$} & \multicolumn{2}{|c|}{ Propensity score-matched cohort } \\
\hline & Study analysis & Subgroup analysis \\
\hline & 81 & 71 \\
\hline Age & 0.030 & 0.031 \\
\hline Male gender & 0 & 0.060 \\
\hline \multicolumn{3}{|l|}{ Aortic valve disease } \\
\hline Stenosis & 0.295 & 0.144 \\
\hline \multicolumn{3}{|l|}{ Valve morphology } \\
\hline Bicuspid & 0.027 & 0.217 \\
\hline \multicolumn{3}{|l|}{ Comorbidities } \\
\hline Symptomatic & 0.215 & 0.029 \\
\hline Arterial HT & 0.166 & 0.034 \\
\hline Pulmonary HT & 0.051 & NA \\
\hline $\mathrm{LVEF} \leq 35 \%$ & 0.047 & 0 \\
\hline Coronary artery disease & 0.037 & 0.101 \\
\hline Atrial fibrillation & 0 & 0.055 \\
\hline History of smoking & 0.151 & 0.093 \\
\hline COPD & 0.179 & 0.055 \\
\hline Diabetes & 0.033 & 0.080 \\
\hline Chronic renal failure & 0.051 & 0.119 \\
\hline Hemodialysis & NA & NA \\
\hline History of stroke & 0 & 0.085 \\
\hline
\end{tabular}

